\title{
EFFICACY OF A DENTAL EXTRACTION POLICY DESIGNED TO PREVENT OSTEORADIONECROSIS: A RETROSPECTIVE STUDY IN 100 ORAL CANCER PATIENTS TREATED WITH INTENSITY-MODULATED RADIOTHERAPY \\ Constantinus Politis ${ }^{1 a^{*}}$ id, Paul Deckers ${ }^{1 \mathrm{~b}}$, Matthias Schol ${ }^{1 \mathrm{~b}}$, Daan Nevens ${ }^{2 c}$, Sandra Nuyts ${ }^{2 \mathrm{~d}}$, Joseph Schoenaers ${ }^{1 \mathrm{e}}$, Reinhilde Jacobs ${ }^{1 f}$
}

'OMFS-IMPATH research group, Department of Imaging \& Pathology, Faculty of Medicine, KU Leuven and Oral and Maxillofacial Surgery, University Hospitals Leuven, BE-3000 Leuven, Belgium

2Department of Oncology, KULeuven - University of Leuven, University Hospitals Leuven - Radiation Oncology, BE-3000, Leuven, Belgium

${ }^{a}$ MD, DDS, MHA, MM, PhD, Professor

${ }^{b} D D S$

MDD

${ }^{\mathrm{d} M D}$, PhD, Professor

eMD, DDS, Professor

${ }^{f} D D S, P h D$, Professor

DOI: 10.25241/stomaeduj.2018.5(3).art.5

Introduction: The aim was to determine the efficacy of an extraction policy designed to prevent osteoradionecrosis (ORN) in dentate areas of the jaw after intensity-modulated radiotherapy (IMRT). A secondary aim was to establish whether our extraction policy risked unnecessary tooth extractions for areas designated to be not-at-risk of ORN.

Methodology: Data were retrospectively collected from 100 oral cancer patients, including the fate of 1430 individual teeth, from diagnosis to follow-up.

Results: Eight percent of IMRT-treated patients developed ORN; spontaneous cases (5) outnumbered those provoked by dental issues (3). All cases of ORN arose in regions irradiated with > $60 \mathrm{~Gy}$, with the posterior mandible as preferred location, with nonspontaneous cases primarily due to progressive periodontitis. No correlation was found between the likelihood of extraction and cancer stage.

Conclusions: A more robust extraction policy of teeth affected with periodontitis and pocket depths of $4-5 \mathrm{~mm}$ might be advocated in molar areas predicted to receive > $60 \mathrm{~Gy}$. Unfortunately, our study's retrospective design precluded any detailed analyses of the underlying reasons for the 88 extractions that occurred at lower radiation dose thresholds; a more conservative approach may therefore be warranted for these low-risk areas.

Keywords: osteoradionecrosis, intensity-modulated radiotherapy, dosimetric distribution, tooth extraction, oral cancer.

OPEN ACCESS This is an Open Access
article under the CC BY-NC 4.0 license.
Peer-Reviewed Article
Citation: Politis C, Deckers P, Schol M, Nevens D, Nuyts
S, Schoenaers J, Jacobs R. Efficacy of a dental extraction
policy designed to prevent osteoradionecrosis: a
retrospective study in 100 oral cancer patients treated
with intensity-modulated radiotherapy. Stoma Edu J.
2018;5(3):173-178
Academic Editor: Nardi Casap-Caspi, DMD, MD,
Professor and Head, Hebrew University Hadassah
Jerusalem, Jerusalem, Israel
Received: September 03, 2018
Revised: September 19, 2018
Acccepted: September 24, 2018
Published: September 25, 2018
*Corresponding author: Prof. Dr. Constantinus
Politis, MD, DDS, MHA, MM, PhD, Department of Oral
and Maxillofacial Surgery, University Hospital Leuven,
Kapucijnenvoer 33, Leuven, BE-3000 Belgium
Tel: +32 16332464; Fax: +32 16332437, e-mail:
constantinus.politis@uzleuven.be
orcid.org/0000-0003-4772-9897
Copyright: $\odot$ 2018 the Editorial Council for the
Stomatology Edu Journal.

\section{Introduction}

Osteoradionecrosis (ORN) of the jaw is a serious complication that can arise following radiotherapy for head and neck cancers [1]. ORN is defined as a slowhealing radiation-induced ischemic necrosis of the bone, associated with varying degrees of soft tissue necrosis in the absence of local primary tumor necrosis, recurrent, or metastatic disease [1]. When radiation is delivered in standard fractions, bone irradiated at doses in excess of $60 \mathrm{~Gy}$ appears to be the most vulnerable to ORN lesions [1]. However, occasionally, lesions arise in bone exposed to lower doses (usually above $50 \mathrm{~Gy}$ but below 60) [2]. Furthermore, ORN lesions may occur spontaneously after radiotherapy, or after trauma, particularly after dental extractions [1].

Pre-treatment dental screens aim to reduce the risk of developing ORN following radiation therapy by removing teeth predicted to be at an increased risk of harboring infection or becoming infected [3].
Frequently, these screens are based on the presumption that conventional external beam radiation therapy will be used, as is the case in our Department of Oral and Maxillofacial Surgery, University Hospitals of Leuven (Leuven, Belgium). However, with the introduction of intensity-modulated radiotherapy (IMRT), a significantly higher proportion of normal tissue is spared from high-dose radiation [4], with these high doses restricted to a smaller area. This leads us to suggest that a modified extraction policy might be appropriate for IMRT patients [5]

To determine which teeth should be left in situ versus those that should be extracted (as a precautionary measure in terms of ORN prevention), clinicians in our department base their decision-making on the outcome of a "single tooth risk assessment" (Table 1), which is used for areas of the mouth at a low risk of developing ORN (i.e. areas < $50 \mathrm{~Gy}$ ).

Teeth which are designated "irrational to treat" in Table 
1) are extracted (leaving those with good prognoses insitu. The fates of teeth with doubtful prognoses are then based on levels of oral hygiene, any limitation in the ability to open the mouth, and the clinical experience of the supervising surgeon: whenever possible these teeth are treated and retained.

For those areas at a high risk of developing ORN $(>50$ Gy), extractions are completed whenever the tooth demonstrates one of the signs/conditions listed in Table 2 [6]. Some teeth are also necessarily sacrificed as part of the surgical resection procedure.

The main objective of this study was to determine the efficacy of the tooth extraction policy in preventing ORN at the Department of Oral and Maxillofacial Surgery, University Hospitals of Leuven (Leuven, Belgium). A highperformance extraction policy would accurately target only those teeth that constitute a risk of promoting ORN. However, two other scenarios, should they be identified, would be of concern as these would indicate failings in the current preventative extraction protocol. These scenarios include a failure to extract teeth that subsequently provoke ORN, or the identification of extractions in the absence of risk (i.e. non irradiated teeth, teeth irradiated with < 50 Gy radiation, or teeth with none of the indications in Table 1).

\section{Materials and Methods}

\subsection{Subjects}

Our 100-patient cohort (with 1430 individual teeth under consideration) comprised patients diagnosed with cancer of the oral cavity between January 2012 and September 2016, at the Department of Oral and Maxillofacial Surgery, University Hospitals of Leuven (Leuven, Belgium). These patients were subsequently treated with IMRT at the Department of Radiotherapy and Oncology, University Hospitals of Leuven (Leuven, Belgium).

All patients underwent pre-IMRT dental screening, after which extractions of compromised teeth were performed: the "irrational to treat" as listed in Table 1, the indications as listed in Table 2, and extractions deemed necessary because of the planned resection procedure. Since clinical, radiographic, and radiotherapeutic documentation were available for all patients, we could retrospectively determine which teeth remained insitu and were present at the time of IMRT. These teeth were subsequently denoted as "not being considered a risk factor for ORN development after IMRT".

Using the individual IMRT plans for each patient, all teeth (including those that were, and were not extracted) were subdivided according to maximum dose, with categories of < 50 Gy (1), 50 - 60 Gy (2), and > 60 Gy (3). This distinction was made because there is still a risk of ORN, albeit reduced [2], even if the total radiation dose delivered by standard fractionation is below $60 \mathrm{~Gy}$ [1]. Patients who developed ORN prior to February 2017 were categorized according to two types of ORN: spontaneous ORN that occurred post IMRT, and ORN caused by a dental issue.

The following data were also collected: patient identification number, date of cancer diagnosis, start date for IMRT, the cause of ORN and its date of diagnosis. To avoid bias, clinicians involved in gathering and processing data were not involved in treatment.
Table 1. Single tooth risk assessment.

\begin{tabular}{|c|c|c|}
\hline Prognosis & Dental field & Criteria \\
\hline Good & - & - \\
\hline \multirow{7}{*}{ Doubtful } & \multirow{3}{*}{ Periodontal } & Furcation involvement (levels II and III) \\
\hline & & Angular bone defects \\
\hline & & $\begin{array}{l}\text { "Horizontal" bone loss exceeding } 2 / 3 \text { of } \\
\text { the root }\end{array}$ \\
\hline & \multirow{3}{*}{ Endodontal } & Incomplete root canal therapy \\
\hline & & Periapical pathology \\
\hline & & Presence of voluminous posts/screws \\
\hline & Dental & Extensive root caries \\
\hline \multirow{9}{*}{$\begin{array}{l}\text { Irrational to } \\
\text { treat }\end{array}$} & \multirow{5}{*}{ Endodontic } & Recurrent periodontal abscesses \\
\hline & & Periodontic-endodontic lesions \\
\hline & & Attachment loss to the apex \\
\hline & & $\begin{array}{l}\text { Root perforation in the apical half of } \\
\text { the root }\end{array}$ \\
\hline & & $\begin{array}{l}\text { Periapical pathology in the presence of } \\
\text { obturating post and core }\end{array}$ \\
\hline & \multirow{3}{*}{ Dental } & Vertical fracture of the root \\
\hline & & $\begin{array}{l}\text { Oblique fracture in the middle third of } \\
\text { the root }\end{array}$ \\
\hline & & $\begin{array}{l}\text { Caries lesions that extend into the root } \\
\text { canal }\end{array}$ \\
\hline & Functional & $\begin{array}{l}\text { Third molars without antagonist and } \\
\text { with periodontitis/caries }\end{array}$ \\
\hline
\end{tabular}

Table 2. Tooth extraction policy for areas predicted to receive a radiation dose > $50 \mathrm{~Gy}$.

\begin{tabular}{l}
$\begin{array}{l}\text { Lesions induced by deep caries that could expose the pulp during } \\
\text { treatment }\end{array}$ \\
\hline $\begin{array}{l}\text { pockets }>6 \mathrm{~mm} \\
\text { furcation involvement }>=\text { level I } \\
\text { mobility }>\text { level I } \\
\text { gingival recession }>=6 \mathrm{~mm} \\
\text { any combination of these periodontal } \\
\text { criteria } \\
\text { in patients that demonstrate poor } \\
\text { cooperation, any tooth with active } \\
\text { periodontitis in the field of radiation is } \\
\text { extracted }\end{array}$ \\
$\begin{array}{l}\text { Active periodontitis } \\
\text { with: }\end{array}$ \\
\hline $\begin{array}{l}\text { Non-restorable teeth with large and/or subgingival restorations } \\
\text { Root caries }\end{array}$ \\
\hline $\begin{array}{l}\text { Teeth with large restorations, combined with severe erosion and } \\
\text { abrasion }\end{array}$ \\
\hline Teeth with a periapical granuloma \\
\hline Avital teeth \\
\hline $\begin{array}{l}\text { Partially impacted or partially erupted teeth that are not fully } \\
\text { covered by bone, or those showing a radiolucency above the crown }\end{array}$ \\
\hline Teeth with cyst formation \\
\hline Teeth showing radiographic abnormalities \\
\hline Teeth with cracked tooth syndrome
\end{tabular}

\subsection{Statistical Analyses}

The primary objective of this study was analyzed statistically by evaluating patient subsets with percentages and confidence intervals, as well as plots of an empirical distribution function. Statistical analyses were supervised by a certified statistician.

\section{Ethical Approval}

This study was approved by the ethical committee of UH Leuven (S54701). 


\section{Results}

In 100 patients, 1770 teeth were absent at intake (Table 3). Management decisions for the 1430 remaining teeth were then made prior to surgery and/or radiation therapy. In total 1031 teeth were left in situ, with 399 extractions. The respective dose predictions for the 399 extracted teeth were as follows: 156 were destined to receive a radiation dose of $<50 \mathrm{~Gy} ; 59$ were projected to receive > 50Gy but < $60 \mathrm{~Gy}$; and 48 extractions were in an area that would receive a dose of $>60 \mathrm{~Gy}$. Another 136 teeth were removed during the surgical procedure due to their position in the resection zone or immediately opposite the free flap.

In those areas predicted to receive a radiation dose of less than $50 \mathrm{~Gy}, 156$ teeth were also extracted: 75 for dental reasons (indications listed in Table 1), and 81 for (other) reasons that could not be established following review of the medical files. Due to the retrospective character of this study, it was impossible to identify the relevant decision-making criteria for these 81 extractions (i.e. limited cooperation of the patient, predictions of poor oral hygiene, or limited ability to open the mouth). Irrespective of the underlying reasons, the extraction policy in these areas more closely resembled the extraction policy used to prevent ORN. Collectively, 22 patients underwent 81 extractions from areas that were either not destined for irradiation, or were destined to be irradiated with a dose of < $50 \mathrm{~Gy}$. One hypothesis that was tested was whether patients with an advanced stage of cancer would undergo more extractions in areas not prone to exhibit ORN of dental origin? Figure 1 shows a scatterplot depicting the correlation between tooth extraction (in each patient) and cancer staging at the tumor level. A linear correlation could not be found. The Spearman's rank correlation coefficient was -0.0314 ( $p$-value $=0.7557$ ). If only those patients that underwent tooth extractions were included, the Spearman's rank correlation coefficient was 0.285 ( $p$-value $=0.1465$ ). Consequently, no correlation was found to exist between the stage of the oral cancer and the tooth extraction policy.

The patients in this study had an average follow-up period of 815 days, or close to 2 years and 3 months after starting IMRT. In total, 8 out of 100 patients developed an ORN lesion, 5 spontaneously, and 3 after an extraction. For the five spontaneous cases (with no link to dental problems), 1 lesion occurred in the maxilla and the other 4 cases were in the mandible. All lesions arose in the body of the mandible, in areas where radiation levels exceeded $60 \mathrm{~Gy}$. Lesion incidence showed a preference for the posterior parts of the jaw in areas corresponding to (6) molars, (3) bicuspids, and (1) canine.

Three patients developed ORN lesions caused by dental problems from the retention of 6 teeth that were presumed to pose (at the time of the extraction decision-making) no risk of ORN.

The average period between commencing IMRT and developing ORN was 438 days, or just over 1 year and 2 months; onset data for individuals (all 8 patients that developed ORN) with follow-up periods for the entire cohort are shown in Figure 2.

All three ORN lesions of dental origin arose in the mandible in areas exposed to a radiation dose of $60 \mathrm{~Gy}$
Table 3. Details of all extractions.

\begin{tabular}{|c|c|c|}
\hline Area & Tooth status & $\begin{array}{c}\text { Number of } \\
\text { teeth }\end{array}$ \\
\hline & Absent at intake & 1770 \\
\hline & Present at intake & 1430 \\
\hline Resection site & $\begin{array}{l}\text { Peroperative removal in } \\
\text { the resection specimen }\end{array}$ & 136 \\
\hline $\begin{array}{l}\text { Irradiated area > } \\
50 \mathrm{~Gy}\end{array}$ & Left in situ & 397 \\
\hline $\begin{array}{l}\text { Irradiated area > } \\
50 \mathrm{~Gy}\end{array}$ & $\begin{array}{l}\text { Extracted for ORN } \\
\text { prevention }\end{array}$ & 76 \\
\hline $\begin{array}{l}\text { Irradiated area > } \\
50 \mathrm{~Gy}\end{array}$ & $\begin{array}{l}\text { Extracted for a dental } \\
\text { reason }\end{array}$ & 31 \\
\hline $\begin{array}{l}\text { Non-irradiated or } \\
<50 \mathrm{~Gy}\end{array}$ & Left in situ & 634 \\
\hline $\begin{array}{l}\text { Non-irradiated or } \\
<50 \mathrm{~Gy}\end{array}$ & $\begin{array}{l}\text { Extracted for a dental } \\
\text { reason }\end{array}$ & 75 \\
\hline $\begin{array}{l}\text { Noni-rradiated or } \\
<50 \mathrm{~Gy}\end{array}$ & $\begin{array}{l}\text { Extracted, reasons not } \\
\text { specified }\end{array}$ & 81 \\
\hline
\end{tabular}

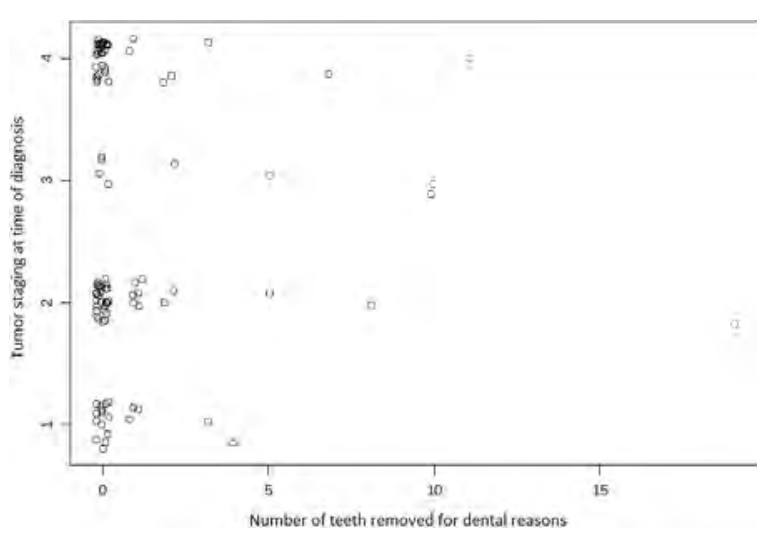

I Figure 1. Scatter plot showing the relationship between the number of teeth removed and tumor size.

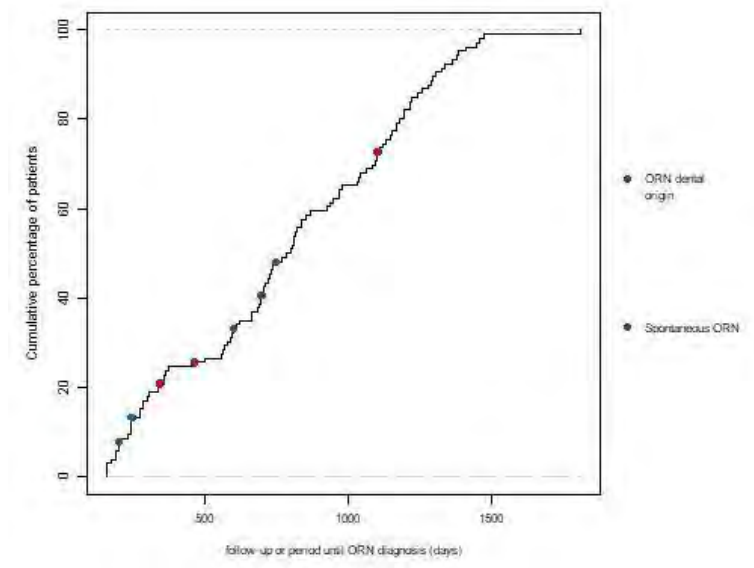

Figure 2. Empirical distribution function showing the follow-up period prior to developing ORN.

or higher. The causal teeth for these lesions were canine (1), bicuspid (3), and molar (2). The medical files did not mention any specific pathological findings at the canine or bicuspids at intake. The molars showed signs of periodontitis with pocket depths of 4 and $5 \mathrm{~mm}$, respectively, at intake. Eventually, these teeth had to be removed as periodontitis had progressed. Either this infection, or the subsequent extraction, triggered ORN.

\section{Discussion}

As early as 1922, the first case of ORN was described by Regaud [7]. In 1926, Ewing followed with an article 
describing bone changes associated with radiation therapy that were termed "radiation osteitis" [8]. Despite the extensive research provoked by these early reports, ORN still poses a substantial threat in patients that have undergone radiation therapy in the head and neck region, especially given the absence of any standard conservative treatment [9], and the frequent requirement for extensive surgery [10].

The first category of ORN that should be addressed is the spontaneous lesion. These can, by definition, not be prevented, even with an adequate extraction policy, as their origin is unrelated to trauma [1]. In this study, all but one spontaneous lesion arose in the mandible, with these results in line with the higher susceptibility of the mandible to ORN versus (vs.) the maxilla $[1,10]$. The overall ratio for ORN incidence for the mandible vs. maxilla was 24:1 [11]. All spontaneous lesions in this study were found in the alveolar ridge, with a preference for more posterior regions. The lesions occurred in areas corresponding to 6 molars, 3 bicuspids, and 1 canine. These findings are also in line with the general consensus that the posterior regions of the jaw are more susceptible to developing ORN lesions $[1,10]$.

The second category of ORN lesion would appear to be preventable given that this category arises following an extraction or by dental infection that occurs in areas of bone exposed to a high level of radiation [1]. The risk of developing ORN because of dental problems in highly irradiated alveolar bone persists for life [12]. Furthermore, there is an increased risk of developing dental caries [13], and periodontal defects [14] after radiation therapy. Teeth predicted to lie in the path of high doses of radiation (> $50 \mathrm{~Gy}$ ) should be in good condition in order to satisfy the criteria for being left in situ without posing a risk of developing $\operatorname{ORN}[6,15,16]$. In this study, ORN caused by dental problems still developed, with three cases identified. This finding indicates that more teeth should have been extracted from the area of high radiation in order to prevent ORN. These findings point to periodontal disease as the greatest hazard, with periodontal pockets of 4-5 $\mathrm{mm}$ present at dental screening that subsequently progressed during follow-up.

It was noted that ORN lesions caused by extractions showed a slight preference to develop in the posterior regions of the alveolar bone, although not to the same extent as spontaneous ORN lesions. The teeth that provoked ORN in the 3 patients were a canine, 3 bicuspids, and 2 molars.

Given that IMRT spares many teeth from high doses of radiation when compared to conventional external beam radiation therapy [4], less teeth are predicted to be at risk to develop ORN lesions. However, the findings of this study fail to account for the higher number of extractions in areas considered to pose no risk of developing ORN (81) vs. the 76 teeth that were at risk (Table 3). It is unclear, due to the retrospective design of this study, as to what triggered the extraction decisions in these scenarios. However, possibilities include poor oral hygiene, future prospects of a limited ability to open the mouth, poor surgical access, an uncooperative patient, or a mistaken evaluation of the area of high radiation. A prospective study should now clarify this aspect of the decision-making process. For those areas not destined to receive $>60$ Gy by IMRT, a more heuristic approach might be beneficial in terms of improving decision-making without bias.

Due to the elevated incidence of oropharyngeal cancers caused by the human papilloma virus (HPV) $[17,18]$, the number of patients at risk of ORN is predicted to rise. The highest doses of radiation will be in the oropharynx itself [19], with a smaller amount affecting the anterior area of the mandible. Therefore, there should be a focus on maintaining the strict extraction criteria for ORN prevention [6] for posterior teeth, particularly those in the mandible, whereas areas with a low risk of ORN should be treated with the less austere general practice guidelines as outlined in Table 1.

In total, 8 out of 100 patients developed an ORN lesion. Recent studies have reported an overall incidence of ORN in IMRT patients treated for oral cavity and oropharyngeal cancer of $25.5 \%$ (mean follow-up of 41 months) [20] and 40\% (after 5 years of follow-up) [21]. The $8 \%$ incidence reported in this study is therefore much lower than average. However, the short average follow-up period of 815 days (just under 2 years and 3 months) may explain this low incidence rate that is predicted to increase with lengthier follow-up.

\section{Conclusions}

This study revealed that, in spite of an existing extraction policy, ORN lesions caused by dental problems still occurred. Since ORN in these patients only developed in areas in receipt of $>60 \mathrm{~Gy}$, primarily in the molar areas, a more robust extraction policy could be warranted for these areas.

This study made a distinction between areas receiving a radiation dose of between 50 and $60 \mathrm{~Gy}$, and those areas that received a higher radiation dose. The results show that all ORN lesions caused by a dental problem occurred in areas of $60 \mathrm{~Gy}$ or higher. As such, a cut-off value of $60 \mathrm{~Gy}$ of radiation may be a good guideline to establish for decision-making processes. The overall incidence of $8 \%(8 / 100)$ ORN after IMRT for oral and oropharyngeal cancer, after a follow-up period of 2.3 yrs., is considered to be low, although this figure is expected to increase with time. Spontaneous ORN ( 5 patients) was more common than ORN caused by dental problems (3 patients).

As for extractions in areas not destined for irradiation, or predicted to receive less than $50 \mathrm{~Gy}$, a heuristic approach to extraction decision-making is warranted. Future prospective studies could clarify the reasoning for those extractions that failed to meet the expected extraction criteria. We anticipate that this approach will benefit patients given that the loss of multiple teeth is debilitating to the irradiated patient, both physically and emotionally.

\section{Author contributions}

$\mathrm{CP}, \mathrm{PD}, \mathrm{MS}$ : Substantial contributions to the design of the work; JS: Drafting the work; SN, DN: Substantial contributions to the acquisition of data; RJ: reviewed the manuscript. 


\section{Acknowledgements}

Much gratitude goes towards Wim Coucke, the professional statistician involved.

\section{References}

1. Chrcanovic BR, Reher P, Sousa AA, Harris M. Osteoradionecrosis of the jaws - a current overview - part 1: Physiopathology and risk and predisposing factors. Oral Maxillofac Surg. 2010;14(1):3-16. doi: 10.1007/s10006-009-0198-9.

[Full text links] [PubMed] Google Scholar (135) Scopus (73)

2. Kluth EV, Jain PR, Stuchell RN, Frich JC Jr. A study of factors contributing to the development of osteoradionecrosis of the jaws. J Prosthet Dent. 1988;59(2):194-201.

[Full text links] [PubMed] Google Scholar (139) Scopus (95)

3. Eliyas S, Al-Khayatt A, Porter RW, Briggs P. Dental extractions prior to radiotherapy to the jaws for reducing post-radiotherapy dental complications. Cochrane Database Syst Rev. 2013;(2):CD008857. doi: 10.1002/14651858.CD008857 pub2

[Full text links] [PubMed] Google Scholar (14) Scopus (9)

4. Galvin JM, Ezzell G, Eisbrauch A, et al. Implementing IMRT in clinical practice: a joint document of the American Society forTherapeutic Radiology and Oncology and the American Association of Physicists in Medicine. Int J Radiat Oncol Biol Phys. 2004; 58(5):1616-1634. doi: 10.1016/j.jrobp.2003.12.008. [Full text links] [PubMed] Google Scholar (294) Scopus (173)

5. Hansen HJ, Maritim B, Bohle GC 3rd, et al. Dosimetric distribution to the tooth-bearing regions of the mandible following intensitymodulated radiation therapy for base of tongue cancer. Oral Surg Oral Med Oral Pathol Oral Radiol. 2012;114(2):e50-e54. doi: 10.1016/j.000o.2012.01.024

[Full text links] [PubMed] Google Scholar (20) Scopus (19)

6. Schuurhuis JM. Evidence of dental screening for oral foci of infection in oncology patients. Doctoral thesis. Groningen, The Netherlands: University of Groningen; 2016.

7. Regaud C. [On the necrosis of the bones attempted by a cancerous process and treated by radiation.] Compt Rend Soc Biol. 1922a;87:427. [Article in French].

8. Ewing J. Radiation osteitis. Acta Radiol. 1926;6:399-412 Google Scholar (280) Scopus (110)

9. Costa DA, Costa TP, Netto EC, et al. New perspectives on the conservative management of osteoradionecrosis of the mandible: A literature review. Head Neck. 2016; 38(11): 1708-1716. doi: 10.1002/hed.24495.

[Full text links] [PubMed] Google Scholar (14) Scopus (8)

10. Grisar K, Schol M, Schoenaers J, et al. Osteoradionecrosis and medication-related osteonecrosis of the jaw: similarities and differences. Int J Oral Maxillofac Surg. 2016;45(12):1592-1599. doi: 10.1016/j.jijom.2016.06.016.

[Full text links] [PubMed] Google Scholar (8) Scopus (7)

11. Perrier M, Moeller P. [Osteoradionecrosis. A review of the literature]. [Article in French]. Schweiz Monatsschr Zahnmed. 1994;104(3):271-277.

Google Scholar (34) Scopus (19)
12. Berger RP, Symington JM. Long-term clinical manifestation of osteoradionecrosis of the mandible: report of two cases. J Oral Maxillofac Surg. 1990; 48(1):82-84.

[Full text links] [PubMed] Google Scholar (14) Scopus (10)

13. Gupta N, Pal M, Rawat S, et al. Radiation-induced dental caries, prevention and treatment - A systematic review. Natl J Maxillofac Surg. 2015;6(2):160-166. doi: 10.4103/0975-5950.183870. [Full text links] [Free PMC Article] [PubMed] Google Scholar (26)

14. Mortazavi $\mathrm{H}$, Baharvand M. Review of common conditions associated with periodontal ligament widening. Imaging Sci Dent. 2016:46(4):229-237. doi: 10.5624/isd.2016.46.4.229. [Full text links] [Free PMC Article] [PubMed] Google Scholar (5) Scopus (2)

15. Peterson DE, Doerr W, Hovan A, et al. Osteoradionecrosis in cancer patients: the evidence base for treatment-dependent frequency, current management strategies, and future studies. Support Care Cancer. 2010;18(8):1089-1098. doi: 10.1007/s00520-010-0898-6. [Full text links] [PubMed] Google Scholar (94) Scopus (63)

16. Ben-David MA, Diamante M, Radawski JD, et al. Lack of osteoradionecrosis of the mandible after intensity-modulated radiotherapy for head and neck cancer: likely contributions of both dental care and improved dose distributions. Int J Radiat Oncol Biol Phys. 2007; 68(2): 396-402. doi: 10.1016/j. ijrobp.2006.11.059.

[Full text links] [Free PMC Article] [PubMed] Google Scholar (191) Scopus (142)

17. Mehanna $H$, Evans $M$, Beasly $M$, et al. Oropharyngeal cancer: United Kingdom National Multidisciplinary Guidelines. J Laryngol Otol. 2016;130(S2):S90-S96. doi: 10.1017/S0022215116000505. [Full text links] [Free PMC Article] [PubMed] Google Scholar (16) Scopus (10)

18. Grisar K, Dok R, Schoenaers J, et al. Difference in human papillomavirus-positive and -negative head and neck cancers in Belgium: an 8-year retrospective, comparative study. Oral Surg Oral Med Oral Pathol Oral Radiol. 2016;121(5):456-460. doi: 10.1016/j.oooo.2015.10.035 Scopus (6)

19. Yao Y, Chen J, Leary CJ, et al. Split-field vs extended-field intensitymodulated radiation therapy plans for oropharyngeal cancer:

Which spares the larynx? Which spares the thyroid? Med Dosim. 2016; 41(2): 148-153. doi: 10.1016/j.meddos.2015.11.003. [Full text links] [PubMed] Google Scholar (3)

20. Raguse JD, Hossamo J, Tinhofer I, et al. Patient and treatmentrelated risk factors for osteoradionecrosis of the jaw in patients with head and neck cancer. Oral Surg Oral Med Oral Pathol Oral Radiol. 2016;121(3):215-221. doi: 10.1016/j.oooo.2015.10.006. [Full text links] [PubMed] Google Scholar (20) Scopus (12)

21. Monnier Y, Broome M, Betz M, et al. Mandibular osteoradionecrosis in squamous cell carcinoma of the oral cavity and oropharynx: incidence and risk factors. Otolaryngol Head Neck Surg. 2011; 144(5): 726-732. doi: $10.1177 / 0194599810396290$.

[Full text links] [PubMed] Google Scholar (43) Scopus (31).

\section{Constantinus POLITIS}

MD, DDS, MHA, MM, PhD, Professor and Chairperson Department of Oral and Maxillofacial Surgery

University Hospitals Leuven Kapucijnenvoer 33, Leuven, Belgium

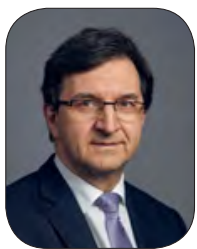

Constantinus Politis is an Oral and Maxillo-Facial Surgeon. He is currently Full Professor and Chairperson of the Department of Oral and Maxillofacial Surgery at Leuven University Hospitals, KULeuven, Belgium. He is an invited Lecturer at the EHSAL in Brussels. He graduated from the Catholic University of Leuven in medicine (MD, summa cum laude), in dentistry (DDS, magna cum laude). He specialized in oral and maxillofacial surgery at the Catholic University of Leuven. His professional field of interest is in orthognathic and orthodontic surgery and trigeminal nerve dysfunction. His clinical research projects include prevention and repair of iatrogenic trigeminal nerve injury, transplantation of teeth and orthognathic surgery. He has been elected as member of the Belgian Royal Academy of Medicine. 


\section{Questions}

\section{ORN occurred in areas irradiated with:}
Da. $<40 \mathrm{~Gy}$;
ab. $<50 \mathrm{~Gy}_{i}$
Dc. $<60 \mathrm{~Gy} ;$
घd. $>60 \mathrm{~Gy}$.

\section{IMRT causes ORN in irradiation of oral and oropharyngeal cancer:}

Da. within the first 3 months after irradiation;

ab. within the first 6 months after irradiation;

ac. within the first 12 months after irradiation;

$\square$ d. usually after the 1 st year of irradiation.

\section{ORN usually does not occur in:}

口a. in the upper jaw;

b. in the ascendic ramus of the lower jaw;

ac. in the dentate area of the lower jaw;

$\square$ d. in the area of the lower jaw where extractions have been done.

\section{The following teeth need not to be extracted if they occur in a zone with 72 Gy of irradiation:}

口a. mobility $>6 \mathrm{~mm}$;

ab. periodontal pocket of $2 \mathrm{~mm}$;

ac. furcation $>1 \mathrm{~mm}$

ad. root caries.
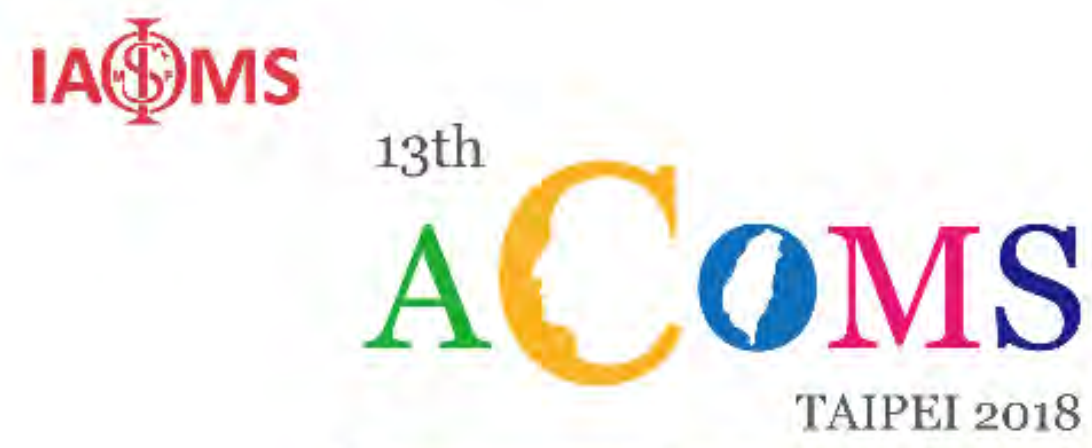

Asian Congress on Oral \& Maxillofacial Surgery

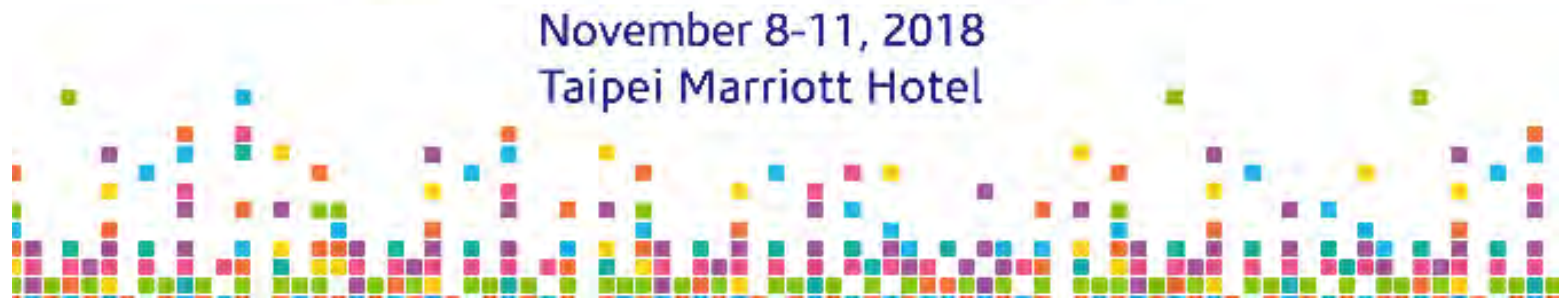

https://2018acoms.com/cms-user/ 